\title{
Uterine Corpus Carcinoma and Carcinosarcoma Pathologic Regional Lymph Nodes TNM Finding v8
}

National Cancer Institute

\section{Source}

National Cancer Institute. Uterine Corpus Carcinoma and Carcinosarcoma Pathologic

Regional Lymph Nodes TNM Finding v8. NCI Thesaurus. Code C139776.

A pathologic finding about one or more characteristics of uterine corpus carcinoma or carcinosarcoma, following the rules of the TNM AJCC v8 classification system as they pertain to staging of regional lymph nodes. 